\title{
MODELLING OF PARTICULATE MATTER FATE ON URBAN HIGHWAY STORMWATER CONTROL SYSTEMS
}

\author{
MARIANA MARCHIONI ${ }^{1}$, ANITA RAIMONDI ${ }^{1}$, UMBERTO SANFILIPPO $^{1}$, JOHN SANSALONE $^{2}$, \\ STEFANO MAMBRETTI ${ }^{1,3}$ \& GIANFRANCO BECCIU ${ }^{1}$ \\ ${ }^{1}$ Politenico di Milano. \\ ${ }^{2}$ University of Florida. \\ ${ }^{3}$ Wessex Institute of Technology.
}

\begin{abstract}
Anthropogenic activities, especially vehicular traffic, produce load of pollutants that accumulate on impervious surfaces. In highways, exhaust, automobile parts wear and lubricating parts along with heavy metals and other pollutants accumulated on the pavement surface during dry periods are the sources of pollution. Rainfall-runoff process promotes surface wash-off, contributing to stormwater pollutants' load. The cumulative load in runoff is normally expressed as an exponential model with a peak concentration at the beginning of the rainfall event known as the first flush, where most part of the load is washed off at the beginning of the event reaching an early peak. This consideration motivates often the use of a first flush storage tank (FFT) to treat stormwater discharge from highways that is then discharged into water courses without any other treatment. It is considered that the FFT would retain the most polluted part of the runoff; however, a weak first flush is observed in some rainfall events, especially for low flow rates. Also, the vehicular traffic occurring during the rainfall event serves as a continuous source. Therefore, the objective of this research is to compare the efficiency on particle removal of an FFT with other methods of stormwater treatment, in this case an infiltration-exfiltration system (IES) consisting of a gravel swale with porous asphalt surface, through hydrological modelling of six rainfall events measured on a highway in Cincinnati (USA). The results showed a compatible removal rate for both the FFT and IES for the six analysed events, consisting of three mass-limit events and three flow-limit events. Particle transport modelling could represent well the behaviour of the events and can be used as a tool to choose between systems, where after setting the particle removal efficiency, other factors can be considered, like cost and system area consumption. This research can be followed up with continuous rainfall simulations and using computational fluid dynamics (CFD) to model IES particle removal.
\end{abstract}

Keywords: first flush tank, infiltration-exfiltration system, permeable pavement, stormwater treatment, SUDs.

\section{INTRODUCTION}

Stormwater is an important source of pollutants into watercourses. Rainfall-runoff process promotes surface wash-off of the accumulated sediments during dry periods. In highways, exhaust, automobile parts wear and lubricating parts along with heavy metals and other pollutants are the sources of pollution. The chemical analysis of stormwater in comparison with wastewater showed a higher presence of heavy metals and comparable or higher values for BOD and chemical oxygen demand (COD). A study held in Hamilton County (Ohio, USA) compared the stormwater runoff with wastewater flow and found an approximately equivalent annual load of total suspended solids (TSS) and COD. Particulate matter (PM) plays the role of a vector for the transport of pollutants such as heavy metals, organics and nutrients, and they end up being washed out by stormwater, eventually reaching streams [1-3]. An optimal solution for stormwater management is treatment of its source, reducing the peak flow and volume within treatment plant limits and including systems that also treat stormwater [4-6]. Best management practices (BMPs) of stormwater and sustainable urban drainage systems (SUDs) include systems, components and practices that favour stormwater 
management at its source, dealing with runoff peak flow, volume and treatment $[7,8]$. This research compares the efficiency of particle removal using two different stormwater control systems, a first flush tank (FFT) and an infiltration-exfiltration system (IES) with a porous surface layer, using data measured from six single rainfall-runoff events in the highway Interstate 75 (I-75) in Cincinnati (Ohio, USA).

\section{METHODOLOGY}

2.1 Experimental site and rainfall events data

Rainfall-runoff samples were collected from an experimental site in Cincinnati that receives runoff contribution from a $15 \times 20 \mathrm{~m}$ area in I-75. Hydrological data is presented in Table 1, which shows three high-intensity events (18/06/1996, 07/07/1996 and 08/08/1996) and three low-intensity events (17/10/1996, 25/11/1996 and 16/12/1996). The highest rainfall intensity and runoff volume was observed on the 07/07/1996 event $(110.17 \mathrm{~mm} / \mathrm{h}$ and $9643 \mathrm{~L}$, respectively) and the lowest on the 25/11/1996 event $(3.05 \mathrm{~mm} / \mathrm{h}$ and $150 \mathrm{~L}$, respectively). More details on the hydrological data can be found elsewhere $[9,10]$.

\subsection{Hydrological modelling}

Stormwater management model (SWMM) was used to simulate the hydrological process of rainfall runoff using kinematic wave [11-13]. Rainfall-runoff models consider hydrological losses by infiltration and depression storage, neglecting evapotranspiration and interception, from vegetation or vehicular traffic [14]. To take account of these hydrological abstractions not considered on the model, the percent of imperviousness and the depression storage were used to reach the best accordance between the model and the measured results.

2.2.1 PM transporting modelling

PM mass accumulates during dry periods in a process known as build-up, which is due to wash-off from surfaces by stormwater during rainfall-runoff events. PM mass accumulation is a function of previous dry period expressed in days (PDD) or hours (PDH) [15-17]. The

Table 1: Hydrologic data from I-75 site [9].

\begin{tabular}{|c|c|c|c|c|c|c|}
\hline $\begin{array}{l}\text { Event } \\
\text { measured }\end{array}$ & $\begin{array}{l}\text { Rainfall } \\
\text { duration } \\
(\mathrm{min})\end{array}$ & $\begin{array}{l}\text { Runoff } \\
\text { volume } \\
\text { (L) }\end{array}$ & $\begin{array}{l}\text { Rain } \\
\text { depth } \\
(\mathrm{mm})\end{array}$ & $\begin{array}{l}i_{\max }^{a} \\
(\mathbf{m m} / \mathbf{h})\end{array}$ & $\begin{array}{l}\mathbf{i}_{\mathrm{avr}}^{\mathbf{b}} \\
(\mathbf{m m} / \mathbf{h})\end{array}$ & $\begin{array}{l}\text { Event } \\
\text { classification }\end{array}$ \\
\hline 18/06/1996 & 63 & 2779 & 11.3 & 55.08 & 15.1 & \multirow{4}{*}{$\begin{array}{l}\text { Mass-limited, } \\
\text { high-runoff } \\
\text { volume events }\end{array}$} \\
\hline 07/07/1996 & 50 & 9643 & 40.4 & 110.17 & 45.96 & \\
\hline 08/08/1996 & 51 & 3877 & 14.1 & 91.44 & 18.95 & \\
\hline 17/10/1996 & 616 & 3693 & 29.1 & 18.36 & 3.04 & \\
\hline 25/11/1996 & 150 & 216 & 3.1 & 3.05 & 1.13 & \multirow{2}{*}{$\begin{array}{l}\text { Flow-limited, } \\
\text { low-runoff } \\
\text { volume events }\end{array}$} \\
\hline $16 / 12 / 1996$ & 340 & 269 & 3.4 & 2.04 & 0.6 & \\
\hline
\end{tabular}

${ }^{\mathrm{a}}$ Maximum rainfall intensity.

${ }^{b}$ Average rainfall intensity. 
EPA SWMM code proposes an empirical exponential model for build-up accumulation according to eqns (1) and (2) [17]:

$$
\begin{gathered}
\mathrm{M}_{\mathrm{a}}(\mathrm{t})=\frac{\text { Accu }}{\operatorname{Disp}} \cdot\left(1-\mathrm{e}^{- \text {Disp } \mathrm{t}_{\mathrm{se}}}\right) \\
\mathrm{t}_{\mathrm{se}}=\mathrm{t}_{\mathrm{sr}}+\frac{1}{\operatorname{Disp}} \cdot \ln \left(\frac{\text { Accu }}{\text { Accu }- \text { Disp } \cdot \mathrm{M}_{\mathrm{ar}}}\right)
\end{gathered}
$$

where $\mathrm{M}_{\mathrm{a}}(\mathrm{t})$ is the accumulated mass function of time $(\mathrm{kg} / \mathrm{ha})$, Accu is the accumulation coefficient rate expressed in $\mathrm{kg} / \mathrm{ha} \mathrm{d}$, Disp is the dispersion coefficient expressed in $\mathrm{d}^{-1}$ and $\mathrm{t}_{\mathrm{se}}$ is the equivalent dry time expressed in days. The value of Accu normally associated with land use ranges from 5 to $35 \mathrm{~kg} / \mathrm{ha} \mathrm{d}$ [16]. This rate may also vary with the characteristics of the surroundings; in [18], similar rates for residential and commercial zones were observed. In literature, the dispersion parameter is estimated to range from 0.08 to $0.4 \mathrm{~d}^{-1}$ and is normally used as calibration with experimental data [16].The equivalent dry time (eqn (2)) considers a residual mass that remains on the watershed after a rainfall-runoff event and is calculated according to eqn (2), where $t_{s r}$ is the real PDD and $\mathrm{M}_{\mathrm{ar}}$ is the mass remaining $(\mathrm{kg})$.

Rainfall-runoff process promotes surface wash-off of the accumulated sediments during dry periods. Previous research on paved urban watersheds demonstrated that the response of solid fraction transport is influenced by the type of event: mass-limited flow limit according to runoff intensity, duration and traffic measured during runoff $[9,12,19,20]$.

Mass-limited events can be described by an exponential model (eqn (3)), whereas flow-limited events are described by a linear model (eqn (4)) [20].

$$
\begin{gathered}
\Delta M_{t}=M_{0}\left(1-e^{-k_{1} V_{T}}\right. \\
\Delta M_{t}=k_{0} V_{T}
\end{gathered}
$$

where $\Delta \mathrm{M}_{\mathrm{t}}$ is the cumulative pollutant mass delivered, $\mathrm{k}$ is the wash-off coefficient and $\mathrm{V}_{\mathrm{T}}$ is the cumulative volume. The cumulative load on runoff for mass-limited events presents a peak concentration at the beginning of the rainfall event, known as the first flush, where most part of the load would be washed off at the beginning of the event, reaching an early peak [9]. Flow-limited events may present a weak first flush. The first flush behaviour can be identified by plotting the normalized cumulative flow volume and mass against the normalized elapsed time, where the first flush occurs when the mass curve is above the flow volume curve. The index event mean concentration (EMC) is often used to characterize concentration; however, it does not indicate temporal variations during events and cannot represent the first flush concept [9]. Typical EMC for TSS in urban areas ranges from 180 to 484.

Build-up and wash-off were modelled for the six registered events using eqns (1), (3) and (4) and SWMM using eqn (1) for build-up and EMC measured for each event for wash-up. The equivalent dry time $\left(\mathrm{t}_{\mathrm{se}}\right)$ was not considered. The EMC measured for each single event can be found in $[9,10]$.

\subsection{Stormwater control}

\subsubsection{First flush separation tank (FFT)}

The first flush concept motivated the development of first flush storage tanks that partition pollutants on a runoff volumetric base when they reach an established accumulated 
volume equal to the first flush storage capacity and would remove most PM mass. FFT is normally designed to retain the first $5 \mathrm{~mm}$ depth of a rainfall event or $50 \mathrm{~m}^{3} / \mathrm{ha}_{\text {imp }}$ (volume for each hectare impermeable of contribution area). The system consists of a diverter that conveys runoff towards the tank until it reaches the full storage capacity. Then the runoff is conveyed directly to the drainage or sewer system. The FFT storage capacity has the most relevant role in pollutant removal on an annual basis (TSS basis), when compared with the number of tanks (one single tank downstream or multiple tanks per watershed) or their kind (transit or capture) [21]. The number of rainfall events with strong first flush will influence pollutants' removal from an FFT, as observed in a study held in Pavia (Italy) which concluded that this type of solution can be cost saving in stormwater management [22]. Partitioning and directing to the sewer system only the stormwater fraction with the highest contaminant concentration improves treatment plant performance [23]. Storage retention time can also promote load removal by sedimentation [24].

In this study, the TS removal efficiency for an FFT with a capacity of $1500 \mathrm{~L}$ was analysed using the hyetograph, accumulated volume and pollutograph for each registered event and modelled data with eqns (3) and (4) and SWMM.

\subsubsection{Infiltration-exfiltration system}

The IES consists of a porous surface and an aggregate base and is placed on road gutters. It functions as a filter for removing the particles from runoff [25]. The porous structure functions to retain particles present in the runoff, reducing the pollutant load [7, 26-28]. The high void content results in less strength; for this reason, permeable pavements are normally applied in areas with low volume traffic and limited heavy vehicle loading [29]. The IES uses permeable pavement technology (pervious concrete or porous asphalt) limited to gutters area with reduced vehicular traffic, therefore allowing application on highways. The filter capacity is defined by the pore media average diameter $\left(\mathrm{d}_{\mathrm{m}}\right)$ and the particle diameter $\left(d_{p}\right)$ that govern the particle transport within the porous media. Three main mechanisms of transport can be distinguished: surface (cake/schmutzdecke), straining filtration and physical-chemical filtration, depending on the average pore diameter and the particle diameter ratio $[2,30]$. Laboratory measurement of a porous asphalt surface with $50 \mathrm{~mm}$ thickness submitted to various loadings, rainfall intensities and durations showed a mass-based particle removal ranging from $88 \%$ to $97 \%$ through cake and straining mechanisms [28]. Data obtained from an IES with $90 \mathrm{~mm}$ pervious concrete and $600 \mathrm{~mm}$ oxide-coated media layers showed a mass-based particle removal from $83 \%$ to $99 \%$. The IES efficiency in particle removal was compared with an FFT, considering the six rainfall events presented in Table 1.

\subsection{Description of goodness-of-fit tests}

The following parameters were chosen to verify if SWMM was effective in capturing the significant components of the storm: peak flow, runoff duration, total volume of flow, runoff coefficient (c) and runoff flow. The criterion used to compare peak flow, time to peak and total volume of flow was percent error, while Nash-Sutcliffe efficiency (NSE) was used for accumulated volume. The measured build-up and wash-off and modelling were analysed using r-squared and percentual error. 


\section{RESULTS}

\subsection{Hydrological modelling}

Rainfall-runoff transformation was modelled using SWMM and goodness-of-fit analysis and is presented in Tables 2 and 3. Considering cumulative volume, high-intensity events presented a compressive better fit when the watershed imperviousness was $100 \%$, whereas in low-intensity events, a better fit was found when the imperviousness was $50 \%$ (Table 2). This could be because the vehicular traffic has more effect on rainfall-runoff process during low-intensity events.

A comparison of measured and modelled parameters considering 100\% imperviousness for high-intensity events, $50 \%$ for low-intensity events and $75 \%$ for all events is presented in Table 3. Overall, high-intensity events showed a better fit than low-intensity events, where the effect of abstractions could be more accentuated. If holding a rainfall continuous simulation, and so using the same modelling parameters for all event types would result in overestimating the runoff volume for low-intensity events and underestimating for high-intensity events, reaching an overall percent error of 3\%. Also, considering $75 \%$ imperviousness, peak flow is underestimated for all rainfall types with a compressive percentual error of $7 \%$.

\subsection{PM transporting modelling}

TS and TSS build-up measured and modelled using eqn (1) is shown in Fig. 1, considering for TS, Accu of $7 \mathrm{~kg} / \mathrm{ha} \mathrm{d}$ and Disp of $0.27 \mathrm{~d}^{-1}$ and for TSS, Accu of $5 \mathrm{~kg} / \mathrm{ha} \mathrm{d}$, Disp of 0.25 $\mathrm{d}^{-1}$. Goodness of fit for wash-off and build-up was also modelled using SWMM, considering the parameters already mentioned for build-up and the single-event EMC for wash-off, obtaining a overestimation for mass from $10 \%$ to $19 \%$.

Table 4. PM mass was obtained through runoff; for this reason, to model build-up, only high-intensity events were considered based on the hypothesis that the entire accumulated surface mass was wash-off with runoff.

Table 2: NSE for total volume.

\begin{tabular}{llll}
\hline Rainfall event & Modelled100 $^{\mathbf{a}}$ & Modelled75 $^{\mathbf{b}}$ & Modelled50 $^{\mathbf{c}}$ \\
\hline 18/06/1996 & 0.86 & 0.91 & - \\
$07 / 07 / 1996$ & 0.72 & 0.97 & - \\
$08 / 08 / 1996$ & 0.81 & 0.17 & - \\
$17 / 10 / 1996$ & - & - & 0.97 \\
$25 / 11 / 1996$ & - & - & 0.88 \\
$16 / 12 / 1996$ & - & & 0.86 \\
${ }^{\text {a Modelled 100, 100\% imperviousness. }}$ & & \\
${ }^{b}$ Modelled 75, 75\% imperviousness. & & \\
${ }^{c}$ Modelled 50, 50\% imperviousness. \\
NSE, Nash-Sutcliffe efficiency.
\end{tabular}


Table 3: Rainfall-runoff modelling goodness of fit.

\begin{tabular}{|c|c|c|c|c|c|c|}
\hline $\begin{array}{l}\text { Rainfall } \\
\text { event }\end{array}$ & Parameter & $\begin{array}{l}\text { Meas- } \\
\text { ured }\end{array}$ & Modelled $^{\mathrm{a}}$ & $\begin{array}{l}\text { Percent } \\
\text { error }\end{array}$ & $\begin{array}{l}\text { Mod- } \\
\text { elled }^{b}\end{array}$ & $\begin{array}{l}\text { Percent } \\
\text { error }\end{array}$ \\
\hline 18/06/1996 & $\mathrm{c}$ & 0.82 & 0.929 & $13 \%$ & 0.697 & $15 \%$ \\
\hline 18/06/1996 & Peak flow (L/min) & 244 & 268.2 & $10 \%$ & 204 & $16 \%$ \\
\hline 18/06/1996 & $\begin{array}{l}\text { Runoff duration, } \\
\text { min }\end{array}$ & 76 & 57 & $25 \%$ & 51 & $33 \%$ \\
\hline 18/06/1996 & Runoff volume (L) & 2779 & 3154 & $13 \%$ & 2367 & $15 \%$ \\
\hline 07/07/1996 & $\mathrm{c}$ & 0.79 & 0.983 & $24 \%$ & 0.737 & $7 \%$ \\
\hline 07/07/1996 & Peak flow (L/min) & 322 & 492 & $53 \%$ & 376.2 & $17 \%$ \\
\hline 07/07/1996 & $\begin{array}{l}\text { Runoff duration } \\
\text { (min) }\end{array}$ & 60 & 67 & $12 \%$ & 61 & $2 \%$ \\
\hline 07/07/1996 & Runoff volume (L) & 9643 & 11928 & $24 \%$ & 8951 & $7 \%$ \\
\hline 08/08/1996 & $\mathrm{c}$ & 0.91 & 0.932 & $2 \%$ & 0.7 & $23 \%$ \\
\hline 08/08/1996 & Peak flow (L/min) & 391 & 400.2 & $2 \%$ & 311.14 & $20 \%$ \\
\hline 08/08/1996 & $\begin{array}{l}\text { Runoff duration } \\
\text { (min) }\end{array}$ & 52 & 45 & $13 \%$ & 63 & $21 \%$ \\
\hline 08/08/1996 & Runoff volume (L) & 3877 & 3266.64 & $16 \%$ & 2451 & $37 \%$ \\
\hline 17/10/1996 & $\mathrm{c}$ & 0.42 & 0.483 & $15 \%$ & 0.725 & $73 \%$ \\
\hline 17/10/1996 & Peak flow (L/min) & 44.3 & 29.4 & $34 \%$ & 42.6 & $4 \%$ \\
\hline 17/10/1996 & $\begin{array}{l}\text { Runoff duration } \\
(\min )\end{array}$ & 609 & 614 & $1 \%$ & 629 & $3 \%$ \\
\hline 17/10/1996 & Runoff volume (L) & 3693 & 3499.8 & $5 \%$ & 5248.62 & $42 \%$ \\
\hline 25/11/1996 & $\mathrm{c}$ & 0.23 & 0.339 & $47 \%$ & 0.509 & $121 \%$ \\
\hline 25/11/1996 & Peak flow (L/min) & 9 & 4.8 & $47 \%$ & 6.6 & $27 \%$ \\
\hline 25/11/1996 & $\begin{array}{l}\text { Runoff duration } \\
\text { (min) }\end{array}$ & 146 & 109 & $25 \%$ & 117 & $20 \%$ \\
\hline 25/11/1996 & Runoff volume (L) & 216 & 259.26 & $20 \%$ & 388.92 & $80 \%$ \\
\hline $16 / 12 / 1996$ & $\mathrm{c}$ & 0.26 & 0.352 & $35 \%$ & 0.528 & $103 \%$ \\
\hline 16/12/1996 & Peak flow (L/min) & 4 & 3.6 & $10 \%$ & 4.8 & $20 \%$ \\
\hline 16/12/1996 & $\begin{array}{l}\text { Runoff duration } \\
\text { (min) }\end{array}$ & 324 & 341 & $5 \%$ & 355 & $10 \%$ \\
\hline $16 / 12 / 1996$ & Runoff volume (L) & 269 & 209.01 & $22 \%$ & 436.5 & $62 \%$ \\
\hline
\end{tabular}

${ }^{\mathrm{a} C o n s i d e r i n g} 100 \%$ imperviousness for high-intensity events (18/06, 7/7 and 8/8) and $50 \%$ imperviousness for low-intensity events $(17 / 10,25 / 11,16 / 12)$.

${ }^{\mathrm{b}}$ Considering $75 \%$ imperviousness. 


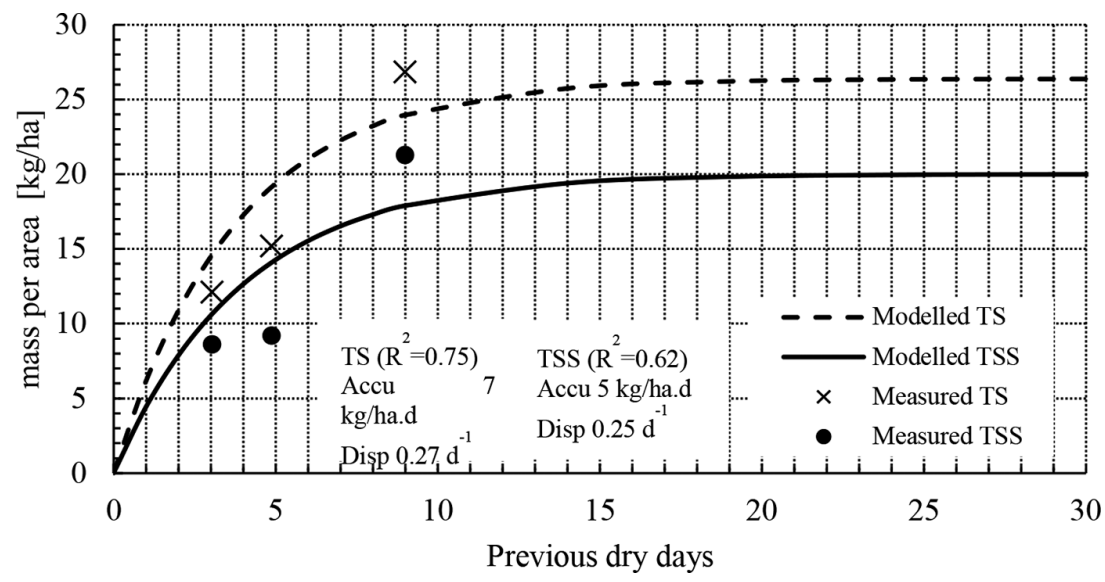

Figure 1: Build-up measured and modelled for TS and TSS, considering the high-intensity rainfall events.

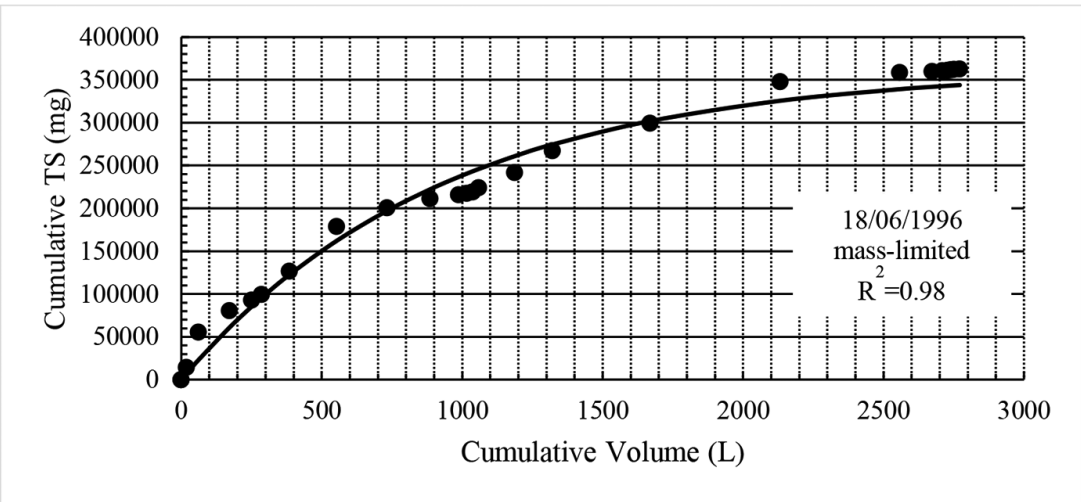

(a)

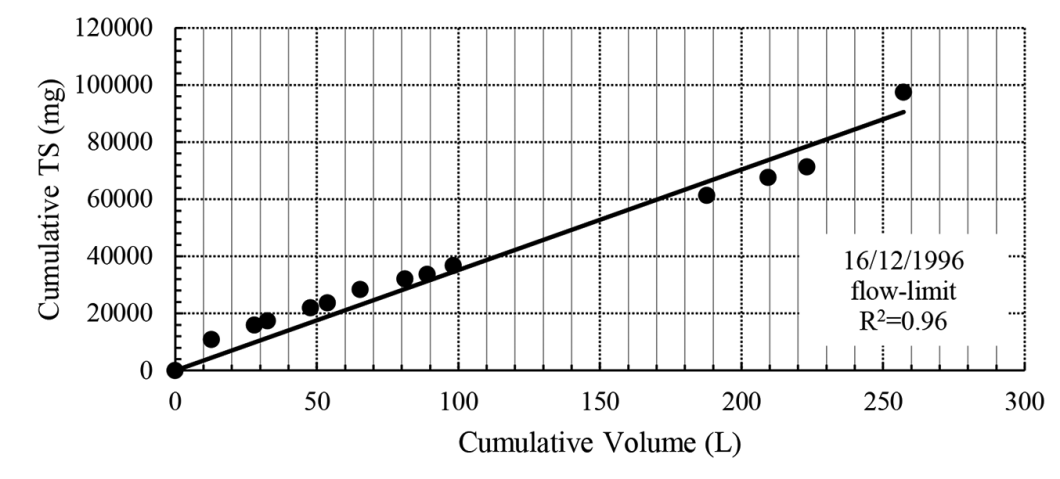

(b)

Figure 2: Measured and modelled particle mass using (a) eqn (3) for TS to the 18/06/1996 rainfall event (mass limited) and (b) eqn (4) for TS to the 16/12/1996 rainfall event (flow limited). 
Table 4: Goodness of fit for build-up and wash-off modelling.

\section{TS}

\begin{tabular}{|c|c|c|c|c|c|}
\hline \multirow{3}{*}{$\begin{array}{l}\text { Rainfall } \\
\text { event }\end{array}$} & \multirow{2}{*}{\multicolumn{2}{|c|}{ Build-up }} & \multicolumn{3}{|c|}{ Wash-off } \\
\hline & & & $\mathbf{R e}$ & ression ${ }^{a}$ & SWMM $^{\mathbf{b}}$ \\
\hline & R-squared & $\begin{array}{l}\text { Percentual } \\
\text { error }^{\mathrm{a}}\end{array}$ & R-squared & $\begin{array}{l}\text { Percentual } \\
\text { error }^{c}\end{array}$ & $\begin{array}{l}\text { Percentual } \\
\text { error }^{c}\end{array}$ \\
\hline 18/06/1996 & 0.75 & $21 \%$ & 0.98 & $5 \%$ & $14 \%$ \\
\hline 07/07/1996 & & $26 \%$ & 0.9 & $3 \%$ & $23 \%$ \\
\hline 08/08/1996 & & $11 \%$ & 0.96 & $9 \%$ & $16 \%$ \\
\hline 17/10/1996 & - & - & 0.96 & $1 \%$ & $19 \%$ \\
\hline 25/11/1996 & - & - & 1 & $3 \%$ & $16 \%$ \\
\hline 16/12/1996 & - & - & 0.96 & $7 \%$ & $10 \%$ \\
\hline
\end{tabular}

TS

\begin{tabular}{|c|c|c|c|c|c|}
\hline \multirow{3}{*}{$\begin{array}{l}\text { Rainfall } \\
\text { event }\end{array}$} & \multirow{2}{*}{\multicolumn{2}{|c|}{ Build-up }} & \multicolumn{3}{|c|}{ wasn-on } \\
\hline & & & $\mathbf{R e}$ & ressiona & SWMM $^{\mathrm{b}}$ \\
\hline & R-squared & $\begin{array}{l}\text { Percentual } \\
\text { error }^{\mathrm{a}}\end{array}$ & R-squared & $\begin{array}{l}\text { Percentual } \\
\text { error }^{c}\end{array}$ & $\begin{array}{l}\text { Percentual } \\
\text { error }^{c}\end{array}$ \\
\hline 18/06/1996 & 0.62 & $25 \%$ & 0.97 & $6 \%$ & $14 \%$ \\
\hline 07/07/1996 & & $54 \%$ & 0.96 & $3 \%$ & $26 \%$ \\
\hline 08/08/1996 & & $15 \%$ & 0.94 & $9 \%$ & $16 \%$ \\
\hline 17/10/1996 & - & - & 0.95 & $1 \%$ & $7 \%$ \\
\hline 25/11/1996 & - & - & 1 & $0 \%$ & $16 \%$ \\
\hline $16 / 12 / 1996$ & - & - & 0.87 & $14 \%$ & $10 \%$ \\
\hline
\end{tabular}

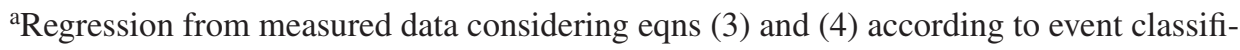
cation.

bSWMM using single-event EMC for quality modelling.

cPercentual error for total event mass in $\mathrm{mg}$.

Figure 2 illustrates wash-off modelling for a mass-limited event using eqn (3) and for a flow-limit event using eqn (4). Modelling underestimated total wash-off mass from $1 \%$ to $9 \%$. Goodness-of-fit analysis for both build-up and wash-off is shown. Wash-off and build-up were also modelled using SWMM, considering the parameters already mentioned for build-up and the single-event EMC for wash-off, in which an overestimation of mass from $10 \%$ to $19 \%$ was obtained.

Wash-off and build-up were also modelled using SWMM, considering the parameters already mentioned for build-up and the single-event EMC for wash-off, which gave an overestimation of mass from $10 \%$ to $19 \%$. 


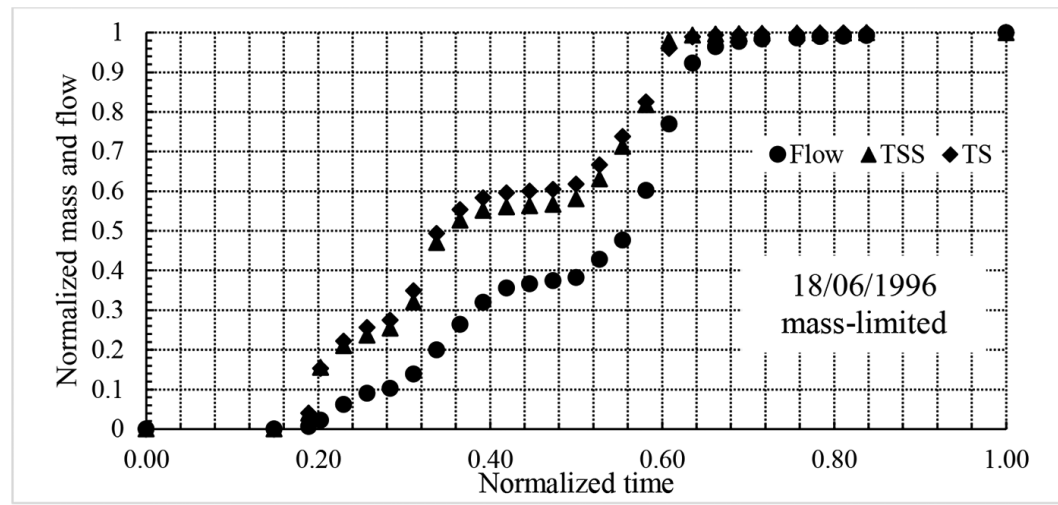

(a)

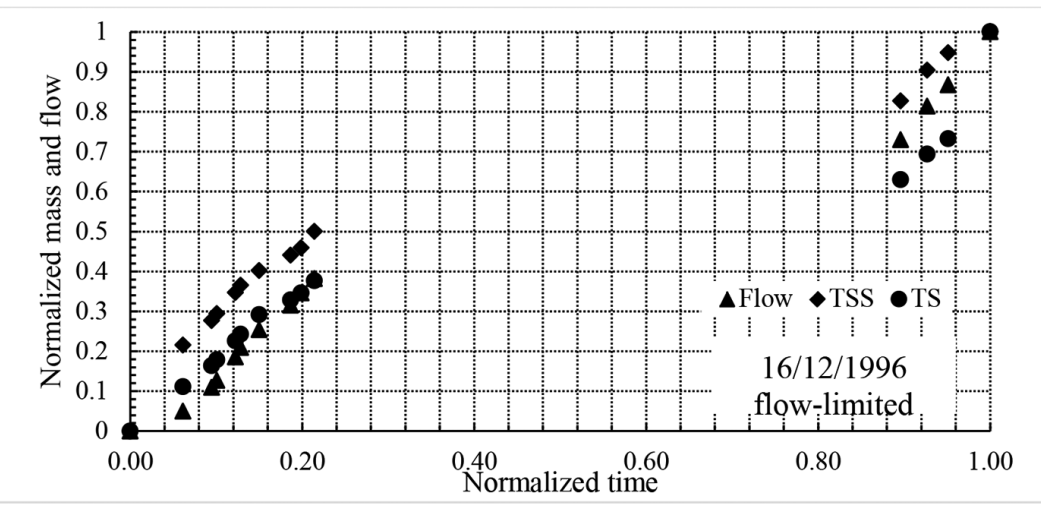

(b)

Figure 3: First flush plots: (a) 18/06/1996 and (b) 16/12/1996 rainfall event.

\subsubsection{First flush analysis}

Normalized mass and flow against normalized time were used to analyse first flush, where a mass curve above flow denoted a first flush behaviour. The 18/06/1996 rainfall event presented a clear first flush typical of a mass-limited event, while for the 16/12/1996 rainfall event, a weak first flush behaviour coherent with flow-limited events was observed (Fig. 3). The same trend was observed for the other events.

\subsection{Stormwater control system}

Considering the six registered single events, an FFT with $1500 \mathrm{~L}$ capacity $(5 \mathrm{~mm}$ rainfall depth) would remove $65 \%$ of TS mass. Two events of low intensity and long duration did not reach a total depth of $5 \mathrm{~mm}$. The established depth of first flush considering for the FFT, and in both cases, the entire event is stored resulting in $100 \%$ removal, even though these events presented a weak first flush, as seen in Fig. 3, for the 16/12/1996 event.

For the 18/06/1996 event, with the highest removal, the FFT trapped the first two mass peaks retaining $75 \%$ of TS mass (Fig. 4). All the results obtained are gathered on Table 5. 


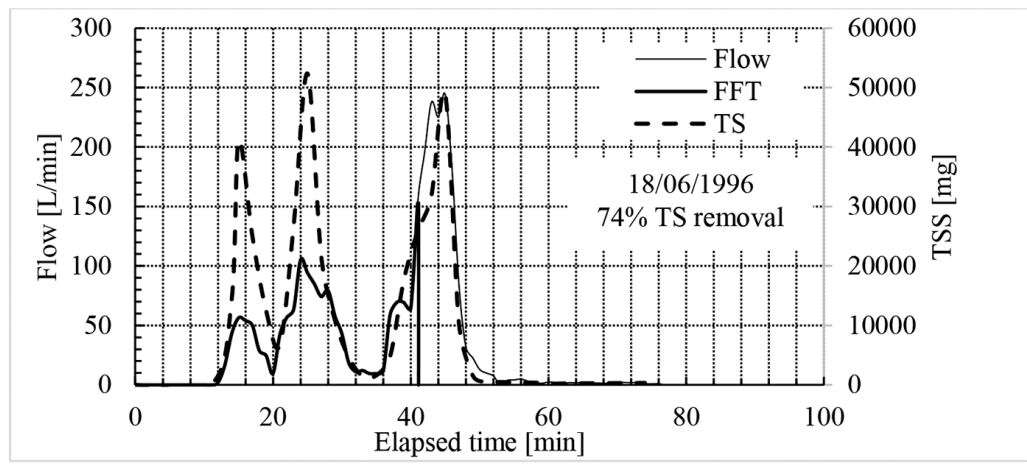

(a)

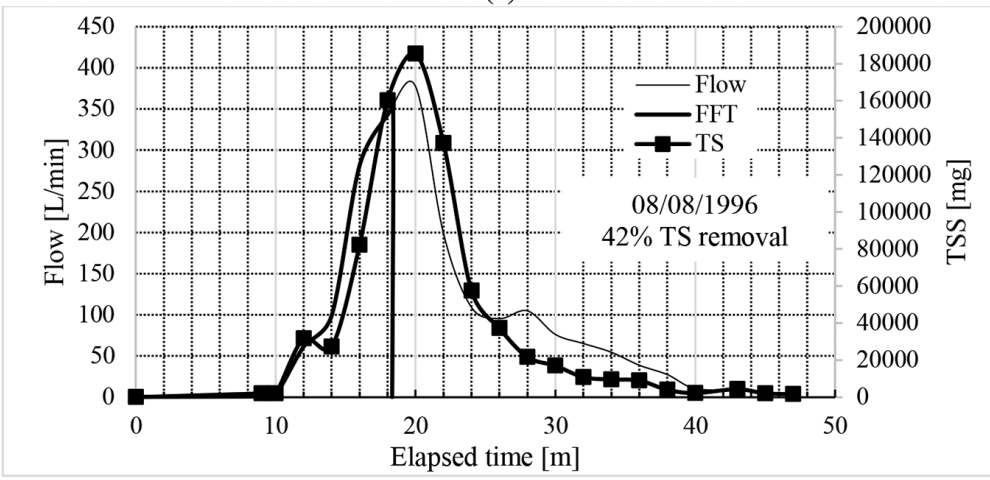

(b)

Figure 4: Runoff and first flush tank (FFT) incoming flow and mass (TS) and cumulative volume and cumulative mass. FFT reaches full storage for $1500 \mathrm{~L}$. Rainfall events: (a) $18 / 06 / 1996$ (b) $08 / 08 / 1996$.

Table 5: FFT particle removal (TS) from measured data, regression model and SWMM.

\begin{tabular}{|c|c|c|c|c|c|c|}
\hline \multirow[b]{2}{*}{$\begin{array}{l}\text { Rainfall } \\
\text { event }\end{array}$} & \multicolumn{2}{|c|}{ Measured $^{\mathbf{a}}$} & \multicolumn{2}{|c|}{ Regression $^{b}$} & \multicolumn{2}{|c|}{$\mathbf{S W M M}^{\mathrm{c}}$} \\
\hline & $\begin{array}{l}\text { Time full } \\
\text { capacity }\end{array}$ & $\begin{array}{l}\text { TS removal } \\
(\%)\end{array}$ & $\begin{array}{l}\text { TS } \\
\text { removal } \\
(\%)\end{array}$ & $\begin{array}{l}\text { Percent } \\
\text { error }^{d} \\
(\%)\end{array}$ & $\begin{array}{l}\text { TS } \\
\text { removal } \\
(\%)\end{array}$ & $\begin{array}{l}\text { Percent } \\
\text { error }^{d} \\
(\%)\end{array}$ \\
\hline 18/06/1996 & 41 & $74 \%$ & $84 \%$ & $8 \%$ & $48 \%$ & $27 \%$ \\
\hline 07/07/1996 & 12 & $58 \%$ & $42 \%$ & $29 \%$ & $13 \%$ & $73 \%$ \\
\hline 08/08/1996 & 18 & $42 \%$ & $67 \%$ & $46 \%$ & $46 \%$ & $7 \%$ \\
\hline 17/10/1996 & 147 & $79 \%$ & $86 \%$ & $9 \%$ & $50 \%$ & $49 \%$ \\
\hline 25/11/1996 & - & $100 \%$ & $100 \%$ & $3 \%$ & $100 \%$ & $16 \%$ \\
\hline 16/12/1996 & - & $100 \%$ & $100 \%$ & $7 \%$ & $100 \%$ & $10 \%$ \\
\hline \multicolumn{2}{|c|}{ TOTAL REMOVAL } & $65 \%$ & $74 \%$ & $9 \%$ & $44 \%$ & $35 \%$ \\
\hline
\end{tabular}

${ }^{\mathrm{a}} \mathrm{TS}$ removal estimated from measured data.

${ }^{b}$ Regression from measured data considering eqns (3) and (4) according to event classification.

${ }^{\mathrm{c}} \mathrm{SWMM}$ using single-event EMC for quality modelling. ${ }^{\mathrm{d}}$ Percent error between measured and modelled data. 
The lowest removal was observed for the 08/08/1996 event. Although the event presented a clear first flush, the FFT storage capacity was reached before the peak mass (Fig. 4). An FFT with 2000 L capacity, corresponding to a $7 \mathrm{~mm}$ depth, would remove $8 \%$ of TS mass.

SWMM modelling underestimated the TS mass removal since the EMC index did not consider a first flush. Considering a TS/TSS ratio from 1.2 to 2.5, a TSS mass removal from $80 \%$ to $95 \%$ by an IES could represents a 50\%-60\% removal of TS. Regression modelling overestimates removal, while SWMM underestimates, not taking into account the first flush effect.

\section{CONCLUSION}

Stormwater from urban paved areas must undergo treatment to comply with discharge regulations and avoid stream and rivers pollution. Source treatment should be encouraged to limit flow that reaches treatment plants. This study compared the particle removal efficiency for two stormwater control systems, an FFT, which relies on the first flush phenomenon, and an IES with porous surface that promotes particle removal through filtration mechanisms. Considering the characteristics and limitations of both systems, the choice between them relies on analysing the local rainfall regime and dominant event behaviour (mass limit or flow limit) to evaluate the feasibility of an FFT or a system based on filtration for the whole event, such as the IES. Modelling particle transport can be an important tool to choose between systems. Using exponential or linear models can represent better mass- or flow-limit events, while EMC does not represent a first flush behaviour, although it is often used. Further steps in this study would consider applying computational fluid dynamics (CFD) to model IES particle removal and to use continuous simulation to observe particle removal in the long term.

\section{REFERENCES}

[1] Sansalone, J., Kuang, X. \& Ranieri, V., Permeable pavement as a hydraulic and filtration interface for urban drainage. Journal of Irrigation and Drainage Engineering, 134(5), pp. 666-674, 2008. https://doi.org/10.1061/(asce)0733-9437(2008)134:5(666)

[2] McDowell-Boyer, L.M., Huntand, J.R. \& Sitar, N., Particle transport through porous media. Water Resources Research, 22(13), pp. 1901-1921, 1986. https://doi. org/10.1029/wr022i013p01901

[3] Marchioni, M.L. \& Becciu, G., Permeable pavement used on sustainable drainage systems (SUDs): a synthetic review of recent literature. WIT Press Urban Water II, p. 12, 2014.

[4] Raimondi, A. \& Becciu, G., Probabilistic design of multi-use rainwater tanks. Procedia Engineering, 70, pp. 1391-1400, 2014. https://doi.org/10.1016/j.proeng.2014.02.154

[5] Becciu, G., et al., Design rainfalls in a climate changing world. WIT Transactions on The Built Environment, p. 139, 2014.

[6] Lamera, C., et al., Green roofs effects on the urban water cycle components. Procedia Engineering, 70, pp. 988-997, 2014. https://doi.org/10.1016/j.proeng.2014.02.110

[7] Marchioni, M. \& Becciu, G., Experimental results on permeable pavements in urban areas: A synthetic review. International Journal of Sustainable Development and Planning, 10(6), pp. 806-817, 2015. https://doi.org/10.2495/sdp-v10-n6-806-817

[8] Raimondi, A. \& Becciu, G., On the efficiency of stormwater detention tanks in pollutant removal, 2017.

[9] Sansalone, J.J., et al., Physical characteristics of urban roadway solids transported during rain events. Journal of Environmental Engineering, 124(5), pp. 427-440, 1998. https://doi.org/10.1061/(asce)0733-9372(1998)124:5(427)

[10] Sansalone, J.J. \& Buchberger, S.G., Partitioning and first flush of metals in urban roadway storm water. Journal of Environmental Engineering, 1997. 
[11] Rossman, L., Storm water management model user's manual - Volume I - Hydrology. Cincinnati: US Environmental Protection Agency, 2010.

[12] Cristina, C.M. \& Sansalone, J.J., Kinematic wave model of urban pavement rainfallrunoff subject to traffic loadings. Journal of Environmental Engineering, 129(7), pp. 629-636. https://doi.org/10.1061/(asce)0733-9372(2003)129:7(629)

[13] Palla, A., Gnecco, I. \& Lanza, L.G., Compared performance of a conceptual and a mechanistic hydrologic models of a green roof. Hydrological Processes, 26(1), pp. 73-84, 2012. https://doi.org/10.1002/hyp.8112

[14] Becciu, G. \& Paoletti, A., Random characteristics of runoff coefficient in urban catchments. Water science and technology, 36(8-9), pp. 39-44, 1997. https://doi.org/10.2166/ wst.1997.0641

[15] Ying, G. \& Sansalone, J., Transport and solubility of Hetero-disperse dry deposition particulate matter subject to urban source area rainfall-runoff processes. Journal of hydrology, 383(3-4), pp. 156-166, 2010. https://doi.org/10.1016/j.jhydrol.2009.12.030

[16] Bolognesi, A., Maglionico, M. \& Artina, S. Un supporto alla gestione delle caditoie stradali mediante simulazione numeriche di lungo periodo. Acqua e Città '09 - Convegno Nazionale di Idraulica Urbana. Milano, 2009.

[17] Huber, W.C., et al., Storm water management model; version 4. Environmental Protection Agency, United States, 1988.

[18] Chow, M.F., Yusop, Z. \& Abustan, I., Relationship between sediment build-up characteristics and antecedent dry days on different urban road surfaces in Malaysia. Urban Water Journal, 12(3), pp. 240-247, 2015. https://doi.org/10.1080/1573062x.2013.839718

[19] Sansalone, J. \& Cristina, C., Gradation-based metal mass prediction utilizing granulometry of snow particulate residuals. Journal of Environmental Engineering, 130(12), pp. 1488-1497, 2004. https://doi.org/10.1061/(asce)0733-9372(2004)130:12(1488)

[20] Sheng, Y., Ying, G. \& Sansalone, J., Differentiation of transport for particulate and dissolved water chemistry load indices in rainfall-runoff from urban source area watersheds. Journal of Hydrology, 361(1-2), pp. 144-158, 2008. https://doi.org/10.1016/j. jhydrol.2008.07.039

[21] Sanfilippo, U., et al., First flush storage tanks of transit or capture kind in runoff networks collecting multiple subcatchments. SIDISA Milano 2012 International Symposium on Sanitary and Environmental Engineering. ANDIS, 2012.

[22] Barco, J., Papiri, S. \& Stenstrom, M.K., First flush in a combined sewer system. Chemosphere, 71(5), pp. 827-833, 2008. https://doi.org/10.1016/j.chemosphere.2007.11.049

[23] Becciu, G. \& Raimondi, A., Probabilistic Analysis of Spills from Stormwater Detention Facilities. WIT Transactions on The Built Environment, p. 139, 2014.

[24] Becciu, G. \& Raimondi, A., Probabilistic analysis of the retention time in stormwater detention facilities. Procedia Engineering, 119, pp. 1299-1307, 2015. https://doi. org/10.1016/j.proeng.2015.08.951

[25] Marchioni, M. \& Becciu, G., Infiltration-exfiltration system for stormwater runoff volume and peak attenuation. International Journal of Safety and Security Engineering, 8(4), pp. 473-483, 2018. https://doi.org/10.2495/safe-v8-n4-473-483

[26] Andrés-Valeri, V.C., et al., Laboratory assessment of the infiltration capacity reduction in clogged porous mixture surfaces. Sustainability, 8(8), p. 751, 2016. https://doi. org/10.3390/su8080751 
[27] Brugin, M., et al., Clogging potential evaluation of porous mixture surfaces used in permeable pavement systems. European Journal of Environmental and Civil Engineering, pp. 1-11, 2017.

[28] Marchioni, M., Porous surfaces for permeable pavement: clogging and filtration mechanisms. DICA. Politecnico di Milano: Italy, p. 158, 2018.

[29] Hein, D.K., Swan, D. \& Schaus, L., Structural and hydrological design of permeable pavements. 2010 Annual Conference of the Transportation Association of Canada, Halifax. Nova Scotia, 2010.

[30] Teng, Z. \& Sansalone, J., In situ partial exfiltration of rainfall runoff. II: Particle separation. Journal of Environmental Engineering, 130(9), pp. 1008-1020, 2004. https://doi. org/10.1061/(asce)0733-9372(2004)130:9(1008) 